TITLE:

\title{
Endozoochorous seed dispersal by sympatric mustelids, Martes melampus and Mustela itatsi, in western Tokyo, central Japan
}

\author{
$\operatorname{AUTHOR}(\mathrm{S}):$ \\ Tsuji, Yamato; Tatewaki, Takafumi; Kanda, Eiji
}

\section{CITATION:}

Tsuii, Yamato ... [et al]. Endozoochorous seed dispersal by sympatric mustelids, Martes melampus and Mustela itatsi, in western Tokyo, central Japan. Mammalian Biology - Zeitschrift für Säugetierkunde 2011, 76(5): 628-633

ISSUE DATE:

2011-09

URL:

http://hdl.handle.net/2433/148237

\section{RIGHT:}

(c) 2011 Deutsche Gesellschaft für Säugetierkunde. Published by Elsevier GmbH; この論文 は著者最終稿です。内容が印刷版と異なることがありますので、引用の際には出版社版 をご確認ご利用ください。This is the Accepted Author Manuscript. Please cite only the published version. 
Tsuji et al. 1

1 Endozoochorous seed dispersal by sympatric mustelids, Martes melampus and Mustela itatsi, in

2 western Tokyo, central Japan

3

$4 \quad$ Yamato Tsuji ${ }^{\mathrm{a}}{ }^{*}$, Takafumi Tatewaki ${ }^{\mathrm{b}}$, and Eiji Kanda ${ }^{\mathrm{c}}$

$5 \quad{ }^{a}$ Primate Research Institute, Kyoto University, Aichi 484-8506, Japan.

$6 \quad{ }^{b}$ Laboratory of Wildlife Ecology, School of Veterinary Medicine, Azabu University, Kanagawa

7 229-8501, Japan.

$8 \quad{ }^{\mathrm{c}}$ Tokyo Wildlife Research Institute, Tokyo 190-0181, Japan

9

10 Type of manuscript: original investigation

11 Running page headline: Seed dispersal by martens and weasels

$12 *$ * Corresponding author; Tel: $+81-568-0539$, fax: $+81-568-0539$

13 E-mail: ytsuji@pri.kyoto-u.ac.jp (Y. Tsuji) 
Tsuji et al. 2

Abstract

We investigated seed dispersal by two sympatric mustelid species, the Japanese marten (Martes melampus) and Japanese weasel (Mustela itatsi), along an intercity forest path in western Tokyo, central Japan, from Jul 2007 to Jul 2008. We aimed to investigate the effect of food/habitat preference of these mustelids (martens are semi-arboreal frugivores while weasels are terrestrial carnivores) on their seed dispersal characteristics, which determine their efficacy as seed dispersers. In total, we analyzed 478 fecal samples collected from the two mustelids $\left(N_{\text {marten }}=381, N_{\text {weasel }}=97\right)$.

The proportions of feces containing seeds for martens and weasels were $81.4 \%$ and $55.7 \%$, respectively. The number of plant species whose seeds were found within the feces were 28 and 17 , respectively. Almost all seeds within feces of both mustelids were intact. The number of plant species whose seeds were found within a single fecal sample ranged from one to four, but no significant difference was detected between the two mustelids. However, marten feces contained a significantly greater number of seeds of most plant species as well as total number of seeds than did weasel feces. The numbers of plant species and seeds represented in marten feces varied seasonally, but those represented in weasel feces did not. Our findings suggest the possibility that both mustelids act in some ways as seed dispersers, although martens seem to disperse a greater diversity and total amount of seeds.

Keywords: endozoochory, Japanese marten, Japanese weasel, seed dispersal 
Introduction

Differences in the ecological niches of animals are often reflected in their feeding ecology, such

as food habits, food handling, and habitat preferences (Begon et al. 1996; Feldhamer et al. 2003).

With respect to seed dispersal, sympatric frugivores showing different food habits might vary in their

efficacy as seed dispersers, both in terms of quantity (the number of seeds dispersed) and quality (the

number of plant species, proportion of intact seeds, and germination rate). Such variation is highly

relevant to the structuring of forest ecosystems. To evaluate the contribution of each animal species

in the dispersal of seeds of a given plant species, we must conduct inter-specific comparisons

regarding the characteristics of seed dispersal. So far, numerous comparative studies have been

conducted for avian seed dispersers (Herrera 1984; Fukui 1996), but few have focused on the

seed-dispersing roles played by mammals (but see Koike et al. 2008).

Mustelids (family Mustelidae) are small- to medium-sized carnivorous mammals with a wide

distribution (Feldhamer et al. 2003). These animals play the roles of middle-level to top predators in

boreal and temperate regions (Buskirk et al. 1994). Mustelids feed on animal materials as well as

fruits (Rosalino and Santos-Reis 2009), and therefore exhibit the potential to disperse seeds that pass

unaffected through their digestive tracts (endozoochory) (Koike and Masaki 2008). However, with

the exception of martens (Martes spp.) (Wilson 1993; Hickey et al. 1999; Otani 2002; Zhou et al. 
Tsuji et al. 4

50

as the number of seeds contained in fecal samples and the percentage of seeds that are destroyed,

both of which serve as quantitative indices of the efficacy of seed dispersal.

We examined seed dispersal in two mustelid species, the Japanese marten Martes melampus and the Japanese weasel Mustela itatsi (hereafter marten and weasel, respectively). Both are endemic to Japan and live sympatrically in the forests of the eastern part of Honshu Island (Ohdachi et al. 2009), though they differ in many respects, including body weight ( ca. 1000-1500 g for martens and 140-470 g for weasels: Ohdachi et al. 2009), home range size (ca. 60-360 ha for martens; Kawauchi et al. 2003: ca. 1-4 ha for the weasels: Sasaki and Ono 1994), and habitat preference (martens are semi-arboreal while weasels are terrestrial: Yasuma 1985). In addition, martens are in part frugivorous (percentages of absolute occurrence of fruit in feces: 5.9-89.9\% (Arai et al. 2003); 52.5-97.9\% (Nakamura et al. 2001)), whereas weasels are not (percentages of absolute occurrence of fruit in feces: 1.6-22.2\% (Yukawa 1968); 3.9-8.9\% (Sekiguchi et al. 2002)).

$$
\text { In this study, we aimed to investigate the effect of food/habitat preference of martens and }
$$
weasels on their seed dispersal characteristics. We predict that the semi-arboreal/frugivorous martens would swallow and excrete a more diverse array and/or greater amount of intact seeds than would the terrestrial/carnivorous weasels.

Materials and methods 
Tsuji et al. 5

68

69

Study site

The study was conducted along the Bonbori Forest Path $\left(36^{\circ} \mathrm{N}, 139^{\circ} \mathrm{E}\right)$ between Hachioji City and Akiruno City, approximately $50 \mathrm{~km}$ west of Tokyo (Fig. 1). The path is ca. $10 \mathrm{~km}$ in length and ca. $5 \mathrm{~m}$ wide, and is almost entirely asphalt-paved. Much of the land surrounding the study site has been developed over the past few decades (Nakamura et al. 2001). The mean annual precipitation and temperature at Hachioji, the nearest weather station to the study site, is $1581.7 \mathrm{~mm}$ and $14.1{ }^{\circ} \mathrm{C}$ (range: $-2.0^{\circ} \mathrm{C}$ to $30.3^{\circ} \mathrm{C}$ ), respectively (Japan Meteorological Agency, http://www.jma.go.jp/jma/index.html). The study site is seldom covered by snow, although snow does occasionally fall during winter. The area is mostly covered with forest vegetation with flowing streams (Fig. 1). The vegetation at the study site is dominated by deciduous-coniferous mixed natural forest, as well as planted coniferous forest species such as Cryptomeria japonica and Chamaecyparis obtusa (Nakamura et al. 2001). In addition to martens and weasels, several carnivorous mammal species, such as red foxes (Vulpes vulpes) and raccoon dogs (Nyctereutes procyonoides), inhabit the study site.

(Fig. 1 should appear here)

\section{Fecal sample collection and size measurement}

$$
\text { We collected mustelid feces during walking or cycling (less than } 10 \mathrm{~km} \cdot \mathrm{hr}^{-1} \text { ) surveys along the }
$$


Tsuji et al. 6

86 forest path on clear days. We conducted these surveys at least once a month between Jul 2007 and

87 Jul 2008 (23 surveys in total: two walking and 21 cycling). We did not collect paste-like fecal

88 samples. When we encountered several parts of mustelid feces in one large clump, we treated them

89 as one sample if the color was uniform, or independent samples if the color varied throughout the

90 clump. We measured the maximum diameter $\left(D_{\max }\right)$ of the collected fecal sample to the nearest 0.05

91 mm using a vernier caliper (THS-30; Niigata Seiki Co., Sanjo, Japan). Tsuji et al. (in press)

92 demonstrated that mustelid species could be distinguished based on fecal size. Using the parameters

93 outlined therein, we classified fecal samples whose $D_{\max }$ ranged from $8.7 \mathrm{~mm}$ to $13.1 \mathrm{~mm}$ as marten

94 feces, while samples whose $D_{\max }$ ranged from $4.3 \mathrm{~mm}$ to $7.2 \mathrm{~mm}$ were attributed to weasels. We

excluded fecal samples whose $D_{\max }$ ranged from $7.2 \mathrm{~mm}$ to $8.7 \mathrm{~mm}$ from the analyses because we

could not be confident of their specific origin. All samples were frozen after collection and stored at

97

$-20^{\circ} \mathrm{C}$ until analysis.

98

99

Fecal analyses

Defrosted feces were washed through a 0.5 -mm-mesh sieve and any seeds remaining in the sieve were identified and counted. Seed identification was based on Nakayama et al. (2000). Using 
Tsuji et al. 7

104 (UX4200H; Shimadzu Co., Kyoto, Japan) to the nearest $0.1 \mathrm{mg}$. Seeds less than $1 \mathrm{~mm}$ were difficult

105 to count directly, so we removed as much of the non digested remains as possible and subsequently

106 counted the seeds in a 1-g sub-sample to estimate the total number of seeds contained within the

107 whole sample. In order to minimize the risk of over/underestimating the seed number, we

108 homogenized the whole sample before sub-sampling. We were only able to measure the size and

109 weight of Elaeagnus sp. (Elaeagnaceae) seeds, and the weight of Rosa multiflora (Rosaceae) seeds

110 once, due to their paucity in our samples.

112 Statistical analyses

113 In accordance with Nakamura et al. (2001), we separated the study period (13 months) into four

114 seasons: spring (Mar-May 2008), summer (Jul-Aug 2007 and Jun-Jul 2008), fall (Sep-Nov 2007),

115 and winter (Dec-Feb Dec 2007 and Jan-Feb 2008). We employed Mann-Whitney U-tests to test for

116 a difference between mustelids in mean seed size (mean seed length) and mean seed weight. We

117 compared the frequency of seed occurrence (in relation to the number of fecal samples analyzed)

118 between the two mustelids for each season using a chi-square goodness-of-fit test. Finally, we

119 employed the generalized linear models (GLMs) to test for effects of season, mustelids species, and

120 their interaction on the number of seeds of each plant species, the total number of seeds in a single

121 fecal sample, and the mean number of plant species whose seeds were found within the feces. We 
Tsuji et al. 8

122 assumed that a Poisson distribution represented the error structure of these data. For these analyses,

123 significance levels $(\alpha)$ were set at 0.05 . All data analyses were carried out using the statistical

124 software R. 2.9.1 (R Development Core Team 2009).

125

126 Results

127 Composition of seeds consumed by the martens

128

In total, we collected 560 fecal samples over the study period, but excluded 82 samples whose

129

$D_{\max }$ ranged from $7.2 \mathrm{~mm}$ to $8.7 \mathrm{~mm}$, thus not allowing us to distinguish their specific origin. We

130 analyzed 381 samples that we classified as marten feces (Table 1). The total proportion of fecal

131 samples that contained seeds was $81.4 \%(310 / 381)$. The proportions of seeds in fecal samples were

132 relatively lower in spring $(67.2 \%, 41 / 61)$ and summer $(57.5 \%, 23 / 40)$, and relatively higher in fall

$133(95.3 \%, 61 / 64)$ and winter $(85.6 \%, 185 / 216)$. We identified the seeds of 28 plant species from the

134 feces of martens, including 23 woody species and five herbaceous species (Table 2). The martens

ingested seeds of wild species, as well as those of the fruit cultivars Citrus junos (Rutaceae) and

Diospyros kaki (Ebenaceae). The number of plant species whose seeds were found within feces of 
Tsuji et al. 9

140 mean number of seeds within a single fecal deposit was $107.9 \pm 126.2$. We identified only three cases

141 in which marten fecal samples contained destroyed seeds: two Celtis sinensis (Ulmaceae) seeds

142 found in the spring and winter, and one Hovenia dulcis (Rhamnaceae) seed found in the winter. Thus,

143 almost all seeds found within the fecal samples were intact.

145 Composition of seeds swallowed by weasels

146 In total, we analyzed 97 fecal samples attributed to weasels during the study period (Table 1).

147 The total proportion of fecal samples that contained seeds was $55.7 \%(54 / 97)$. These proportions

148 were relatively lower in spring $(44.5 \%, 10 / 23)$ and summer $(40.0 \%, 6 / 15)$, and relatively higher in

149 the fall $(63.6 \%, 7 / 11)$ and winter $(64.6 \%, 31 / 48)$. We identified the seeds of 17 plant species,

150 including 16 woody species and one herbaceous species, within the fecal samples of the weasels

151 (Table 2). The weasels ingested the seeds of wild plants as well as those of the cultivar D. kaki. With the exception of Physalis alkekengi (Solanaceae), the weasels did not ingest seeds of herbaceous plants. The number of plant species whose seeds were found within feces of the weasels was greatest in winter (11 species), followed by fall (six species) and spring (four species), and was lowest in summer (two species) (Table 1). The mean seed length and weight were $3.86 \pm 2.22 \mathrm{~mm}$ (range: 
158 fecal samples during the study period.

159

160

161

162

163

164

166

167

168

169

170

171

172
(Fig. 2 and Table 1 should appear here)

Comparison of seeds ingested by martens and weasels

The percentages of seeds recorded in each season did not differ between martens and weasels

(chi-square goodness-of-fit tests, spring: $\chi^{2}=0.660, d f=1, P=0.417$, summer: $\chi^{2}=0.158, d f=1, P=0.691$, fall: $\chi^{2}=0.286, d f=1, P=0.593$, winter: $\chi^{2}=1.004, d f=1, P=0.316$ ), nor did the total percentage of seeds identified per sample collected $\left(\chi^{2}=1.459, d f=1, P=0.227\right)$. Five plant species were identified in the feces of both mustelids in the spring, two in the summer, four in the fall, and nine in the winter (Table 1). No differences were observed in either seed length (Mann-Whitney $U$-tests, $d f_{I}=28$, $\left.d f_{2}=17, U=249.5 P=0.797\right)$ or seed weight $(U=248.5, P=0.815)$ between the two mustelids. The GLM shows that mustelid species, season, and their interaction all significantly affect the numbers of seeds represented in the feces from 10, nine, and four out of the 28 plant species observed, respectively $(P<0.05$; Table 1$)$. The GLM also detected the effect of mustelid species $(z=9.74, P<0.001)$, season $(z=-7.55, P<0.001)$, and their interaction $(z=7.04, P<0.001)$ as factors affecting the total number of seeds contained in the feces (Table 1): the feces of martens contained a greater amount of seeds than those of the weasels in spring and winter, but this pattern was not observed in summer and fall (Fig. 2a). However, the GLM did not identify any of these factors as affecting the mean number of plant species whose seeds were found within feces (mustelid species: 
$z=0.51, P=0.611$, season: $z=0.48, P=0.630$, species $\times$ season: $z=0.75, P=0.452$; Fig. $2 b$ ).

Discussion

(Fujii et al. 1998; Koike and Masaki 2008; Kaneko et al. 2009), a detailed examination of their role number of total identified fruits on which European weasels (Mustela nivalis and M. putoris) fed 
Tsuji et al. 12

We predicted that semi-arboreal/frugivorous martens would swallow and excrete a greater

amount of intact seeds and/or seeds from a greater diversity of plant species than the more

terrestrial/carnivorous weasels. As we predicted, the total number of seeds within a single marten

fecal sample contained more seeds (both within each species and in total) than that from a weasel.

This difference may be due to differences in the number of $S$. praecox seeds in spring and of $A$.

arguta seeds in winter, both of which were more abundant within marten feces. Habitat preference seems to be an important factor affecting this difference: terrestrial weasels can only access fruits found on the ground, while semi-arboreal martens have access to fruits on the ground as well as in the trees, such as those of $S$. praecox during the spring before they drop, as well as $A$. arguta fruits in the winter that did not drop in the fall.

Contrary to our prediction, however, we did not observe a significant difference in the number of seeds contained in the feces (both within each species and in total) between the two mustelids in the summer and fall. This result can be attributed to seasonal changes in the staple foods of the two mustelids. In summer and fall, martens mainly feed on animal matter which is abundant in these seasons (Tatara and Doi 1994; Kusui and Kusui 1998; Nakamura et al. 2001), while weasels feed consistently on animal matter throughout the year (Yukawa 1968; Sasaki and Ono 1994; Sekiguchi et al. 2002). Therefore, the relative value of fruit is reduced for martens in summer and fall, likely causing the absence of a clear difference in fruit feeding between the two mustelids in these seasons. 
Tsuji et al. 13

212 This implies that dispersal characteristics of martens reported in this study might simply reflect their

213 generalist feeding behavior.

214 As we predicted, martens ingested seeds from a larger variety of plants (28 species) than did

215 weasels (17 species). Contrary to our prediction, however, no significant difference was observed in

216 the mean number of plant species whose seeds were found within a single fecal deposit between the

217 two mustelids. This discrepancy between the diversity of plant species detected and the lack of

218 diversity of species number found within a single feces can be attributed to the short intestine and

219 consequential short digestion time of the mustelids (4.1-4.6 hrs, Hickey et al. 1999). That is, for both

220 martens and weasels, only the contents of a single fruit feeding bout are likely to be excreted in a

221 single fecal deposit.

222

To be an effective seed disperser, fruit consumers cannot destroy the seeds they ingest, but also

they are expected to enhance (or at least have a neutral effect on) seed germination during its transit

through the gut (Pollux et al. 2007, Rosalino et al. 2010). As for mustelids, several studies have

shown that gut transit significantly enhanced the germination of seeds of many plant species (Hickey

et al, 1999; Zhou et al., 2008), while other studies have shown deleterious effects (Rosalino et al. 
Tsuji et al. 14

230 that they could be less efficient (less specialized) dispersers. An evaluation of the impact of fruit

231 consumption on seed survival is necessary in the future. By confirming the effects of passage

232 through the mustelid gut on seed viability, we can gain a clearer understanding of how each mustelid

233 species varies in its dispersion of viable seeds from various plant species, which will ultimately

234 determine differences in their contribution to the structuring of forest ecosystems

235

236 Acknowledgments

237

We thank Mrs. T. Harasaki of Gifu University and volunteer students from Azabu University for

their assistance in fecal analysis, and Dr. M. A. Huffman for his constructive comments on an earlier

version of the manuscript. We also thank Dr. S. Takatsuki for his advice regarding seed

identification.

Begon, M., Harper, J.L., Townsend C. R. 1996. Ecology (3rd ed). Blackwell Science, 
Tsuji et al. 15

Fujii, T., Maruyama, N., Kanzaki, N. 1998. Seasonal changes in food habits of Japanese weasel in a middle stream of the Tamagawa River. Mammalian Science 38, 1-8 (in Japanese with English summary).

Fukui, A. 1996. Retention time of seeds in bird guts: costs and benefits for fruiting plants and frugivorous birds. Plant Species Biology 11, 141-147.

Herrera, C.M. 1984. A study of avian frugivores, bird-dispersed plants, and their interaction in Mediterranean scrublands. Ecological Monographs 54, 1-23.

Herrera, C.M. 1989. Frugivory and seed dispersal by carnivorous mammals, and associated fruit characteristics, in undisturbed Mediterranean habitats. Oikos 55, 250-262.

Hickey, J.R., Flynn, R.W., Buskirk, S.W., Gerow, K.G., Wilson, M.F. 1999. An evolution of a mammalian predator, Martes americana, as a disperser of seeds. Oikos 87, 499-508.

Kaneko, Y., Shibuya, M., Yamaguchi, N., Fujii, T., Okumura, T., Matsubayashi, K., Hioki, Y. 2009. Diet of Japanese weasels (Mustela itatsi) in a sub-urban landscape: implications for year-round persistence of local populations. Mammal Study 34, 97-106.

Kawauchi, N., Yamamoto, Y., Imai, K. 2003. Annual changes in testicular plasma testosterone concentration, home range and active time in wild male marten, Martes melampus melampus. Mammalian Science 43, 93-98 (in Japanese with English summary). 
Tsuji et al. 16

by literature. Journal of Japan Forestry Society 90, 26-35 (in Japanese with English summary).

267

268

269

270

271

272

273

274

275

276

277

278

279

280

281

282

283

Koike, S., Morimoto, H., Goto, Y., Kozakai, C., Yamazaki, K. 2008. Frugivory of carnivores and seed dispersal of fleshy fruits in cool-temperate deciduous forests. Journal of Forest Research, $15,215-222$.

Kusui, H., Kusui, Y. 1998. Food habits of the Japanese marten Martes melampus (Wagner, 1840) in Mt. Yamato-Katsuragi (2) studies of year to year variation. Wildlife in Kii Peninsula 4, 13-19 (in Japanese).

Nakamura, T., Kanzaki, N., Maruyama, N. 2001. Seasonal changes in food habits of Japanese martens in Hinode-cho and Akiruno-shi, Tokyo. Wildlife Conservation Japan 6, 15-24 (in Japanese with English summary).

Nakayama, S., Inokuchi, M., Minamitani, T. 2000. Encyclopedia of Plant Seeds of Japan. Tohoku University Press, Sendai (in Japanese).

Ohdachi, S.D., Ishibashi, Y., Iwasa, M.A., Saitoh, T. (eds) 2009. The Wild Mammals of Japan. Shoukadoh, Tokyo.

Otani, T. 2002. Seed dispersal by Japanese marten Martes melampus in the subalpine shrubland of northern Japan. Ecological Research 17, 29-38.

Pollux, B.J.A., Ouborg, N.J., van Groenendael, J.M., Klaassen, M. 2007. Consequences of intraspecific seed-size variation in Sparganium emersum for dispersal by fish. Functional 
Ecology 21, 1084-1091.

R Development Core Team 2009. R: a language and environment for statistical computing, version

2.9.1. Vienna: R Foundation for Statistical Computing.

Rosalino, L.M., Santos-Reis, M. 2009. Fruit consumption by carnivores in Mediterranean Europe.

Rosalino, L.M., Rosa, S., Santos-Reis, M. 2010. The role of carnivores as Mediterranean seed dispersers. Annales Zoologici Fennici 47, 195-205.

Sasaki, H., Ono, Y. 1994. Habitat use and selection of the Siberian weasel Mustela sibirica coreana during the non-mating season. Journal of Mammalogical Society of Japan 19, 21-32.

Sekiguchi K., Ogura, G., Sasaki, T., Nagayama, Y., Tsuha, K., Kawashima, Y. 2002. Food habits of introduced Japanese weasels (Mustela itatsi) and impacts on native species on Zamami Island. Mammalian Science 42, 153-160 (in Japanese with English summary). and leopard cat in the Tsushima islands, Japan. Ecological Research 9, 99-107. to discriminate Japanese marten (Martes melampus) and Japanese weasel (Mustela itatsi). Journal of Zoo and Aquarium (in Japanese with English summary). 
Tsuji et al. 18

302 Yasuma, S. 1985. Animal watching: wild mammals of Japan. Shobunsha, Tokyo (in Japanese).

303 Yukawa, H. 1968. On the food habit of the Japanese weasel (Mustela sibirica itatsi Temminck) in

304 northern parts of Hiroshima Pref. Hiwa Science Museum Report 12, 7-10 (in Japanese).

305 Zhou, Y., Slade, E., Newman, C., Wang, X., Zhang, S. 2008. Frugivory and seed dispersal by the

306 yellow-throated marten, Martes flavigula, in a subtropical forest of China. Journal of Tropical

307 Ecology 24, 219-223. 
Tsuji et al. 19

308 Figure Legends

309 Figure 1. Map of the study site. Contours show 100-m intervals.

310 Figure 2. Boxplots for seasonal changes in the (a) total number of seeds within a single fecal deposit,

311 and the (b) mean number of plant species whose seeds were found within a single fecal sample.

312 marten (M), $\square$ : weasel (W). Spring: Mar-May, summer: Jun-Aug, fall: Sep-Nov, winter: Dec-Feb.

313 Bold lines represent medians. Open circles show outliers. Samples without seeds were excluded

314 from the analyses. *: $P<0.05$. 


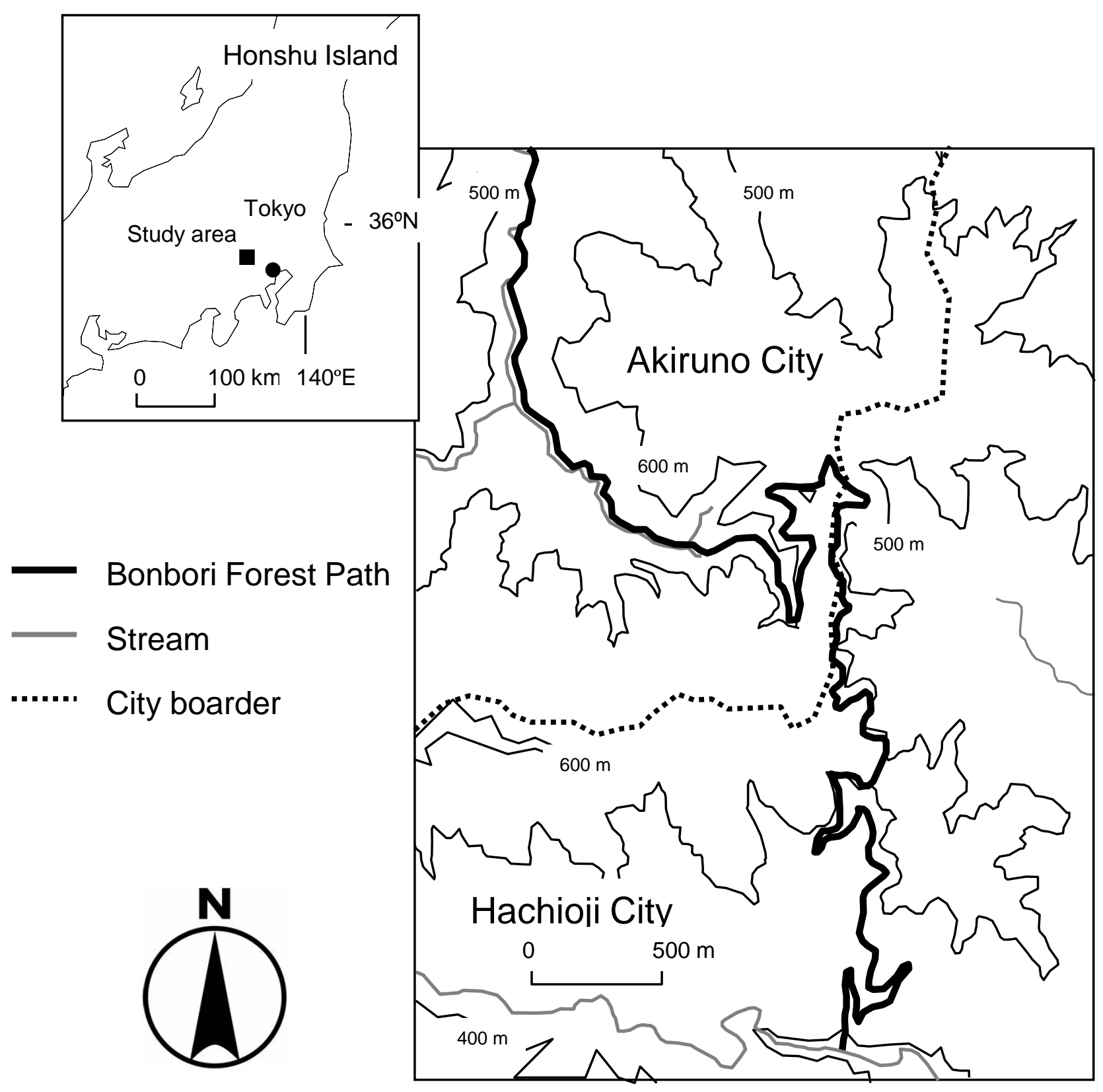




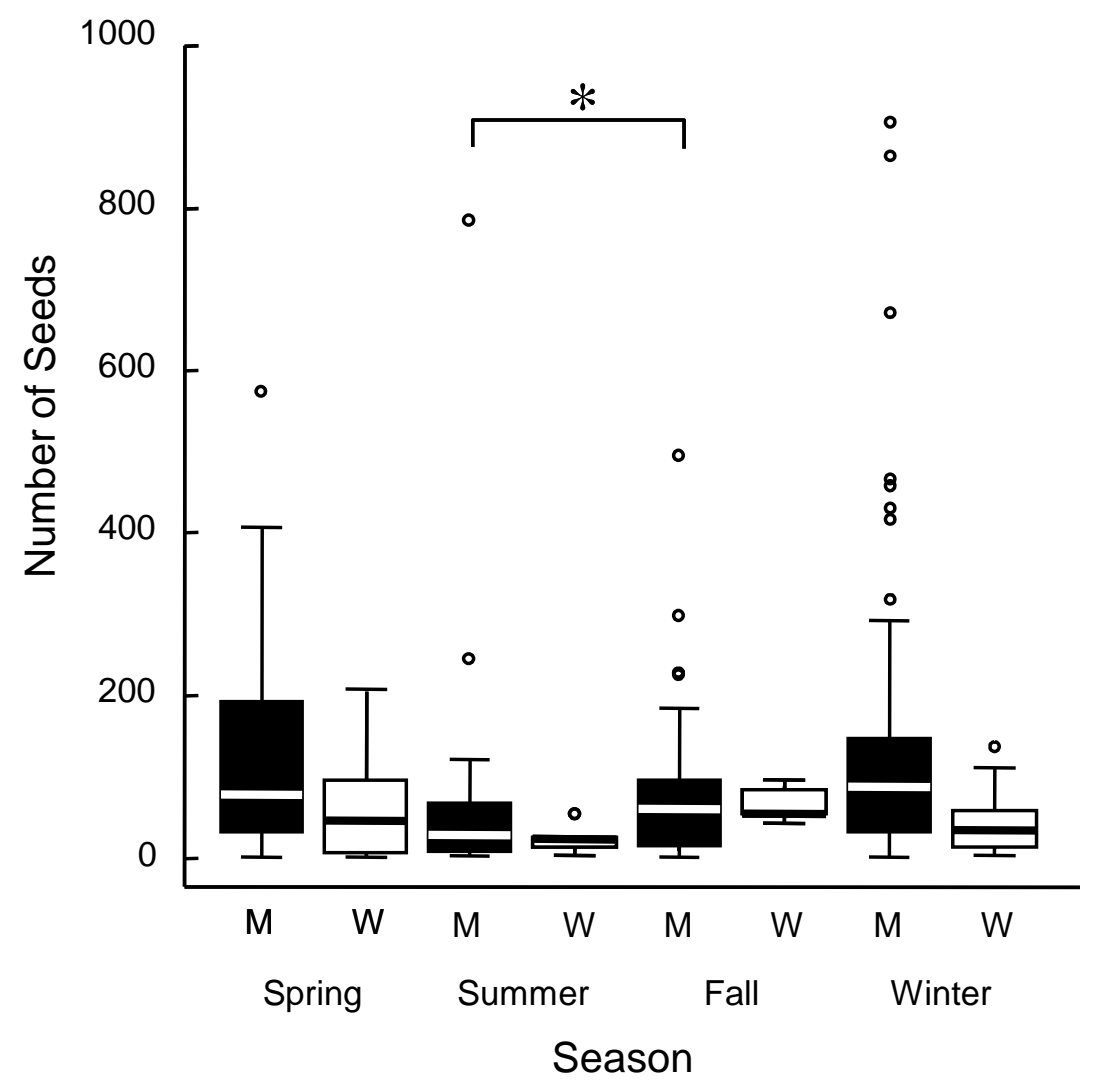

a)

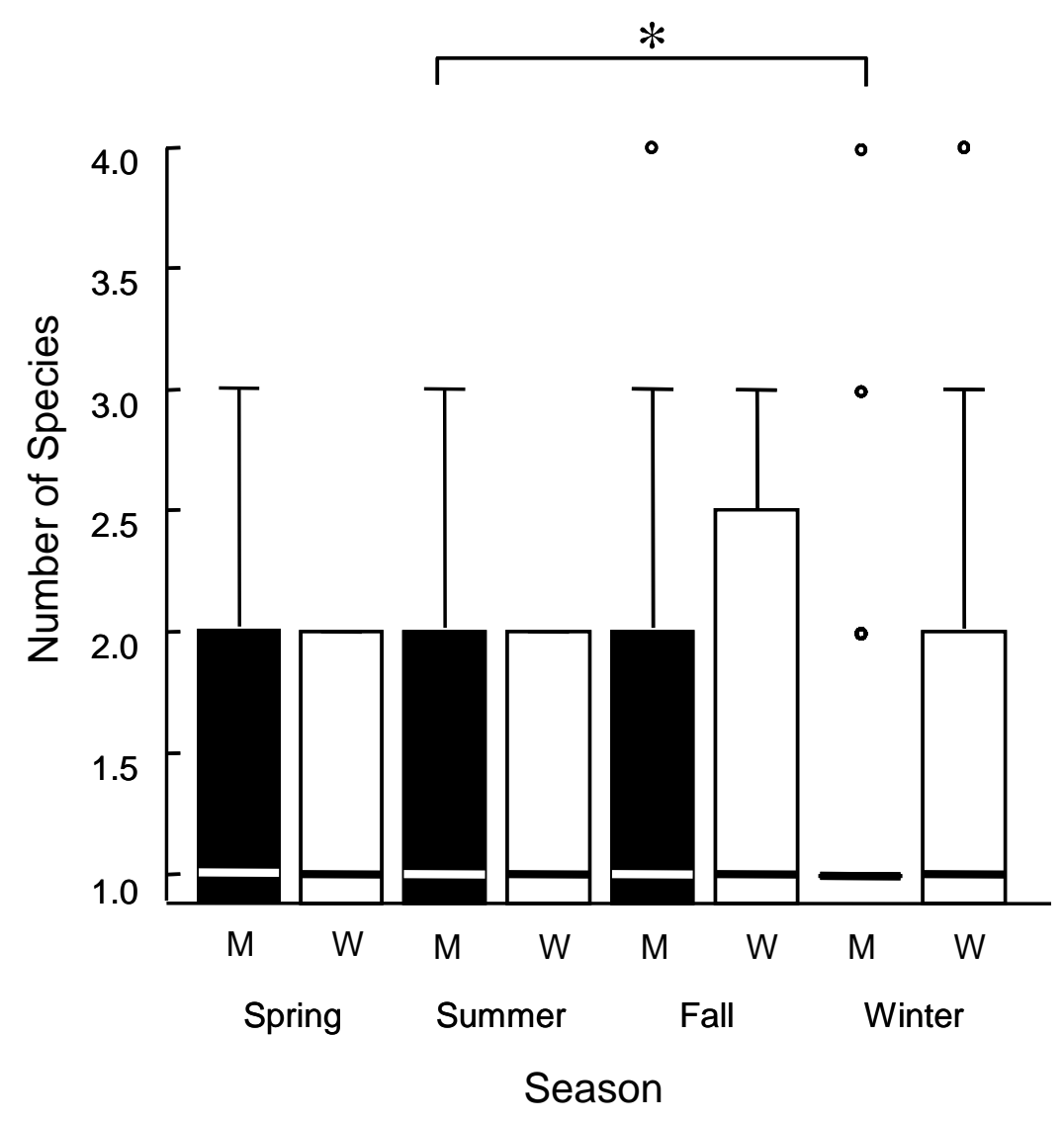

b) 
Table 1. Seasonal changes in mean $\pm S D$ number of seeds within fecal samples of the martens and the weasels at Bonbori Forest Path, central Japan from 2007 to 2008. $\mathrm{N}$ means number of collected fecal samples. Figures in parenthesis mean number of fecal samples containing seeds of given species.

\begin{tabular}{|c|c|c|c|c|c|c|c|c|c|c|c|c|c|c|c|c|c|c|c|c|c|c|c|c|c|c|c|c|c|c|c|c|c|}
\hline \multirow{3}{*}{\begin{tabular}{l}
\multicolumn{1}{c}{ Species } \\
Woody Plant \\
Stachyurus praecox
\end{tabular}} & \multirow{2}{*}{\multicolumn{8}{|c|}{\begin{tabular}{lc}
\multicolumn{2}{c}{ Spring (Mar - May) } \\
Marten $(\mathrm{N}=61)$ & Weasel $(\mathrm{N}=23)$
\end{tabular}}} & \multirow{2}{*}{\multicolumn{8}{|c|}{\begin{tabular}{cc}
\multicolumn{2}{c}{ Summer (Jun - Aug) } \\
Marten $(\mathrm{N}=40)$ & Weasel $(\mathrm{N}=15)$
\end{tabular}}} & \multirow{2}{*}{\multicolumn{8}{|c|}{$\begin{array}{c}\text { Fall (Sep - Nov) } \\
\end{array}$}} & \multicolumn{8}{|c|}{ Winter $(\mathrm{Dec}-\mathrm{Feb})$} & \multirow{3}{*}{$\begin{array}{l}\text { Species }(\mathrm{Sp}) \\
-10.99=\end{array}$} \\
\hline & & & & & & & & & & & & & & & & & & & & & & & & Weasel (N=11) & \multicolumn{4}{|c|}{ Marten $(\mathrm{N}=216)$} & \multicolumn{4}{|c|}{ Weasel $(\mathrm{N}=48)$} & \\
\hline & 134.1 & \pm & 1718 & (15) & & + & & & & & & & & & & & & & 12 & (3) & & - & & & & & 125 & (31) & & & 15 & (3) & \\
\hline Morus bombycis & 95.9 & \pm & 113.0 & (16) & 11.3 & \pm & 10.7 & (3) & 76.2 & \pm & 24.8 & (6) & 37.1 & \pm & 26.6 & (2) & 1.1 & - & & & & - & & & & - & & (Ji) & & - & & (ग) & $-10.88=0 * *$ \\
\hline Actinidia arguta & 73.3 & \pm & 59.1 & (15) & 95.8 & \pm & 75.9 & (6) & & 3.0 & & (1) & & - & & & 61.5 & \pm & 60.4 & (38) & 160.7 & \pm 2 & 271.8 & (7) & 121.7 & \pm & 114.4 & (160) & 45.1 & \pm & 36.4 & (21) & $17.89^{* * *}$ \\
\hline Aphananthe aspera & & 9.0 & & (1) & & - & & & & - & & & & - & & & & - & & & & - & & & & - & & & & - & & & n.a. \\
\hline Prunus jamasakura & 8.0 & \pm & 6.1 & (11) & 4.5 & \pm & 4.7 & (4) & & - & & & & - & & & & - & & & & - & & & & - & & & & - & & & $-2.22^{*}$ \\
\hline Hovenia dulcis & 2.0 & & 1.4 & (2) & & - & & & & - & & & & - & & & & - & & & & - & & & & 1.0 & & (1) & 4.0 & \pm & 3.5 & (3) & $1.33^{\text {n.s. }}$ \\
\hline Pyrus pyrifolia & 1.5 & \pm & 0.7 & (2) & & 1.0 & & (1) & & - & & & & - & & & & - & & & & - & & & 4.5 & \pm & 0.7 & (2) & & 1.0 & & (1) & $-0.03^{\text {n.s. }}$ \\
\hline Celtis sinensis & & 1.0 & & (1) & & - & & & & - & & & & - & & & 12.2 & \pm & 4.8 & (5) & & 4.0 & & (1) & 7.6 & \pm & 7.9 & (8) & & 15.0 & & (1) & $-2.05^{*}$ \\
\hline Diospyros kaki & & 1.0 & & (1) & & - & & & & - & & & & - & & & 8.3 & \pm & 6.8 & (3) & & - & & & 3.9 & \pm & 3.3 & (11) & 1.5 & \pm & 1.0 & (4) & $-2.60^{* *}$ \\
\hline Citrus junos & & 1.0 & & (1) & & - & & & & - & & & & - & & & & - & & & & - & & & & 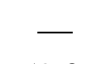 & & & & - & & & n.a. \\
\hline Cinnamonum camphora & & - & & & & 4.0 & & (1) & & - & & & & - & & & & - & & & & - & & & & 59.0 & & (1) & & - & & & n.a. \\
\hline Ilex macropoda & & - & & & & - & & & & 240.0 & & (1) & & - & & & 179.3 & \pm & 273.2 & (3) & & - & & & & - & & & & - & & & n.a. \\
\hline Rubus sp. & & - & & & & - & & & 170.6 & \pm & 343.5 & (5) & 19.0 & \pm & 7.1 & (2) & & - & & & & - & & & 104.0 & \pm & 185.4 & (4) & & - & & & $-13.24^{* * *}$ \\
\hline Akebia sp. & & - & & & & - & & & & - & & & & - & & & 57.8 & \pm & 57.4 & (30) & 2.0 & \pm & 1.4 & (2) & 15.5 & \pm & 20.7 & (4) & & - & & & $-6.50^{* * *}$ \\
\hline Actinidia polygama & & - & & & & - & & & & - & & & & - & & & & 29.0 & & (1) & & 21.0 & & (1) & & 12.0 & & (1) & & - & & & $-1.13^{\text {n.s. }}$ \\
\hline Sorbus sp. & & - & & & & - & & & & - & & & & - & & & & 7.0 & & (1) & & - & & & & 1.0 & & (1) & 14.5 & \pm & 15.2 & (6) & $2.66^{* *}$ \\
\hline Viburnum dilatatum & & - & & & & - & & & & - & & & & - & & & & 2.0 & & (1) & & - & & & & - & & & & \pm & 9.2 & (2) & n.a. \\
\hline Cocculus trilobus & & - & & & & - & & & & - & & & & - & & & & 1.0 & & (1) & & - & & & & - & & & & 10.0 & & (1) & n.a. \\
\hline Elaeagnus sp. & & - & & & & - & & & & - & & & & - & & & & 1.0 & & (1) & & - & & & & - & & & & - & & & n.a. \\
\hline Rosa multiflora & & - & & & & - & & & & - & & & & - & & & & - & & & & - & & & & 41.0 & & (1) & & - & & & n.a. \\
\hline Eurya japonica & & - & & & & - & & & & - & & & & - & & & & - & & & & - & & & & 13.0 & & (1) & 23.5 & \pm & 23.3 & (2) & $1.89^{\text {n.s. }}$ \\
\hline Vitis sp. & & - & & & & - & & & & - & & & & - & & & & - & & & & - & & & & & 1.0 & (3) & & - & & & n.a. \\
\hline Ilex pedunculosa & & - & & & & - & & & & - & & & & - & & & & - & & & & - & & & & 2.0 & & (1) & & - & & & n.a. \\
\hline Herbaceous Plant & & & & & & & & & & & & & & & & & & & & & & & & & & & & & & & & & \\
\hline Polygonaceae sp. & & 1.0 & & (1) & & - & & & & - & & & & - & & & & - & & & & - & & & & - & & & & - & & & n.a. \\
\hline Physalis alkekengi & & - & & & & - & & & & - & & & & - & & & 202.0 & \pm & 256.0 & (2) & & - & & & & 800.0 & & (1) & & 26.0 & & (1) & $-17.20^{* * *+}$ \\
\hline Poaceae species & & - & & & & - & & & 3.5 & \pm & 2.1 & (2) & & - & & & 8.5 & \pm & 6.2 & (3) & & - & & & & 1.0 & & (1) & & - & & & $-1.90^{+}$ \\
\hline $\begin{array}{l}\text { Total number of seeds } \\
\text { \# Species detected }\end{array}$ & 92.0 & $\begin{array}{c} \pm \\
13 \\
\end{array}$ & 128.8 & (41) & 28.0 & $\begin{array}{c} \pm \\
6\end{array}$ & & (10) & 44.1 & $\begin{array}{l} \pm \\
5\end{array}$ & 127.1 & $\frac{(23)}{(23)}$ & 8.7 & $\begin{array}{l} \pm \\
\end{array}$ & 14.7 & (6) & 74.6 & $\begin{array}{l} \pm \\
13 \\
\end{array}$ & $3^{82.1}$ & (61) & 41.4 & $\begin{array}{l} \pm \\
4 \\
\end{array}$ & 34.7 & (7) & 99.0 & \pm & $\begin{array}{ll}125.3 \\
17\end{array}$ & $(185)$ & 24.5 & $\begin{array}{l} \pm \\
11\end{array}$ & 32.3 & (31) & $9.74^{m+m e n}$ \\
\hline
\end{tabular}

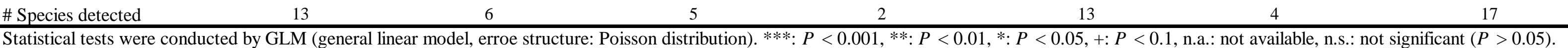


Table 2. Physical characteristics of seeds included within the feces of martens and weasels at Bonbori Forest Path, central Japan from 2007 to 2008. ${ }^{a} \mathrm{Y}$ : appeared within feces, $\mathrm{N}$ : not appeared within feces. ${ }^{\mathrm{b}}$ Measured only once. *: planted species.

\begin{tabular}{|c|c|c|c|c|c|c|c|c|c|}
\hline \multirow{2}{*}{$\frac{\text { Species }}{\text { Woody Plant }}$} & \multirow[t]{2}{*}{ Family } & \multirow[t]{2}{*}{ Marten $^{a}$} & \multirow[t]{2}{*}{ Weasel } & \multicolumn{3}{|c|}{ Seed Length $(\mathrm{mm}$, Mean \pm SD) } & \multicolumn{3}{|c|}{ Seed Weight (mg, Mean \pm SD } \\
\hline & & & & & & & & & \\
\hline Aphananthe aspera & Ulmaceae & $\mathrm{Y}$ & $\mathrm{N}$ & 3.47 & \pm & 0.62 & 19.0 & \pm & 10.1 \\
\hline Celtis sinensis & Ulmaceae & $\mathrm{Y}$ & $\mathrm{Y}$ & 6.14 & \pm & 0.50 & 102.5 & \pm & 88.7 \\
\hline Morus bombycis & Moraceae & $\mathrm{Y}$ & $\mathrm{Y}$ & 1.43 & \pm & 0.27 & 10.6 & \pm & 7.6 \\
\hline Akebia sp. & Lardizabalaceae & $\mathrm{Y}$ & $\mathrm{Y}$ & 5.59 & \pm & 0.23 & 30.2 & \pm & 29.3 \\
\hline Cocculus trilobus & Menispermaceae & $\mathrm{Y}$ & $\mathrm{Y}$ & 4.82 & \pm & 0.53 & 22.5 & \pm & 3.5 \\
\hline Actinidia arguta & Actinidaceae & $\mathrm{Y}$ & $\mathrm{Y}$ & 2.64 & \pm & 0.24 & 4.8 & \pm & 6.6 \\
\hline Actinidia polygama & Actinidaceae & $\mathrm{Y}$ & $\mathrm{Y}$ & 1.61 & \pm & 0.19 & 4.6 & \pm & 4.8 \\
\hline Eurya japonica & Theaceae & $\mathrm{Y}$ & $\mathrm{Y}$ & 1.94 & \pm & 0.22 & 0.7 & \pm & 0.8 \\
\hline Rubus sp. & Rosaceae & $\mathrm{Y}$ & $\mathrm{Y}$ & 1.60 & \pm & 0.07 & 14.0 & \pm & 25.7 \\
\hline Sorbus sp. & Rosaceae & $\mathrm{Y}$ & $\mathrm{Y}$ & 4.40 & \pm & 0.15 & 4.5 & \pm & 2.6 \\
\hline Cinnamonum camphora & Rosaceae & $\mathrm{Y}$ & $\mathrm{Y}$ & 3.31 & \pm & 0.31 & 64.5 & \pm & 74.2 \\
\hline Rosa multiflora & Rosaceae & $\mathrm{Y}$ & $\mathrm{N}$ & 2.38 & \pm & 0.40 & \multicolumn{3}{|c|}{$1.0^{\mathrm{b}}$} \\
\hline Pyrus pyrifolia & Rosaceae & $\mathrm{Y}$ & $\mathrm{Y}$ & 5.47 & \pm & 0.71 & 336.0 & \pm & 634.6 \\
\hline Prunus jamasakura & Rosaceae & $\mathrm{Y}$ & $\mathrm{Y}$ & 5.80 & \pm & 0.22 & 81.7 & \pm & 19.4 \\
\hline Citrus junos* & Rutaceae & $\mathrm{Y}$ & $\mathrm{N}$ & 11.83 & \pm & 1.60 & 88.6 & \pm & 45.3 \\
\hline Ilex macropoda & Aquifoliaceae & $\mathrm{Y}$ & $\mathrm{N}$ & 4.64 & \pm & 0.28 & 7.9 & \pm & 1.2 \\
\hline Ilex pedunculosa & Aquifoliaceae & $\mathrm{Y}$ & $\mathrm{N}$ & 4.22 & \pm & 0.08 & 15.8 & \pm & 13.0 \\
\hline Hovenia dulcis & Rhamnaceae & $\mathrm{Y}$ & $\mathrm{Y}$ & 3.65 & \pm & 0.50 & 8.8 & \pm & 9.8 \\
\hline Vitis sp. & Vitaceae & $\mathrm{Y}$ & $\mathrm{N}$ & 3.98 & \pm & 0.24 & 34.7 & \pm & 50.8 \\
\hline Elaeagnus spp. & Elaeagnaceae & $\mathrm{Y}$ & $\mathrm{N}$ & \multicolumn{3}{|c|}{$19.4^{\mathrm{b}}$} & \multicolumn{3}{|c|}{$200.0^{\mathrm{b}}$} \\
\hline Stachyurus praecox & Stachturaceae & $\mathrm{Y}$ & $\mathrm{Y}$ & 1.64 & \pm & 0.11 & 1.5 & \pm & 1.1 \\
\hline Diospyros kaki* & Ebenaceae & $\mathrm{Y}$ & $\mathrm{Y}$ & 9.24 & \pm & 0.36 & 98.7 & \pm & 19.8 \\
\hline Viburnum dilatatum & Caprifoliaceae & $\mathrm{Y}$ & $\mathrm{Y}$ & 5.05 & \pm & 0.29 & 14.7 & \pm & 12.8 \\
\hline \multicolumn{10}{|l|}{ Herbaceous Plant } \\
\hline Poaceae sp. A & Gramineae & $\mathrm{Y}$ & $\mathrm{N}$ & 3.17 & \pm & 0.27 & 8.3 & \pm & 12.5 \\
\hline Poaceae sp. B & Gramineae & $\mathrm{Y}$ & $\mathrm{N}$ & 2.75 & \pm & 0.35 & 35.7 & \pm & 55.6 \\
\hline Polygonaceae sp. & Polygonaceae & $\mathrm{Y}$ & $\mathrm{N}$ & 2.49 & \pm & 0.27 & 7.3 & \pm & 9.8 \\
\hline Amphicarpaea sp. & Leguminisae & $\mathrm{Y}$ & $\mathrm{N}$ & 3.77 & \pm & 0.36 & 24.1 & \pm & 20.4 \\
\hline Physalis alkekengi & Solanaceae & $\mathrm{Y}$ & $\mathrm{Y}$ & 1.30 & \pm & 0.17 & 1.4 & \pm & 0.4 \\
\hline
\end{tabular}

